\title{
Near-Field Coseismic Displacement Attenuation Characterization Associated with Japan Mw9.0 Earthquake from High-rate GPS Array Observables
}

\author{
GAO Shuzhao, CHEN Qiang \\ Faculty of Geosciences and Environmental Engineering, \\ Southwest Jiaotong University, \\ Chengdu, China \\ szgao@home.swjtu.edu.cn
}

\begin{abstract}
The accurate investigation on the coseismic displacement attenuation pattern plays an important role in seismic intensity zoning. A new model combining the Logistic Power and Cosine model is proposed in this paper to evaluate the correlation between coseismic displacement and epicentral distance and rupture angle. The presented model is tested and validated using the high-rate GPS array displacement observables associated with Japan Mw 9.0 earthquake. The computation results show that the Logistic Power model is feasible to characterize the pattern between the coseismic displacement and epicentral distance, and the Cosine model between the coseismic displacement and rupture angle.
\end{abstract}

Key Words - coseismic displacement, attenuation pattern, Logistic Power model, Cosine model, high-rate GPS array

\section{INTRODUCTION}

The huge energy released from high-magnitude earthquake can cause elastic or inelastic movement of upper crust. Some seismic parameters, such as acceleration, velocity and displacement, are often introduced to characterize the ground motion ${ }^{[1,2]}$. The coseismic displacement field contains comprehensive effect of seismic wave pulse and time duration. It can be used to characterize the destructive effect caused by earthquake on a large scale. The value of ground displacement is affected by the magnitude, seismic source parameters and propagation way. The investigation on the attenuation pattern plays an important role for seismic intensity zoning ${ }^{[3,4]}$.

Joyner \& Boore established the logarithmic relationship attenuation model between seismic peak ground acceleration (PGA) and magnitude, epicentral distance, propagation media property (rock/soil) ${ }^{[5]}$. Ambraseys \& Srbulov modified the model and established the relationship between peak ground displacement (PGD) and magnitude, epicentral distance and the critical acceleration ratio ${ }^{[6]}$. The predictive equations of PGD derived by Chen Peishan considered the influence of the magnitude, the tectonic ambient shear stress value, epicentral distance and propagation media absorption coefficient ${ }^{[7]}$.

However, it has to be noted that the seismic data for the above model is limited in earlier time. The satellite geodesy after 1990s provides a new technology to obtain high precision seismic displacement field in a wide area. Especially in the recent decade, the dense high-rate GPS continuous operation arrays are gradually set up in some active crustal area, such as Europe, Japan and New Zealand regions. In order to further characterize the attenuation pattern, a new model is proposed and validated using Japanese GPS Earth Observation Network (GEONET) coseismic displacement observables.

\author{
SHAO Yuping \\ Institute of Reservoir Earthquake, \\ Earthquake Administration of Sichuan Province, \\ Chengdu, China
}

\section{DATA SET}

GEONET maintained by Japan Geographical Survey Institute (GSI) is the largest high-rate GPS array in the world ${ }^{[8]}$. There are more than 1000 GPS sites over the country with the average adjacent distance about $25 \mathrm{~km}$. The Mw 9.0 earthquake, occured off the coast of northwest Honshu on Mar 11, 2011, caused a large number casualties and property losses. The GEONET high-rate GPS receiver recorded the displacement data of whole seismic process.

GSI has authorized the observation data to a few research organizations, for example, Advanced Rapid Imaging and Analysis (ARIA) team from JPL and Caltech, Nippon GPS Data Services Company (NGDS). The derived results from NGDS contain about 140 minutes $1-\mathrm{Hz}$ three-dimensional displacement time series at 414 sites in eastern Japan with the starting time UTC 03:59:45, Mar 11, 2011. Because of power failure and other possible reasons, 18 observation sites broke down immediately after the earthquake. The spatial distribution for the 396 working sites is shown as figure 1 .

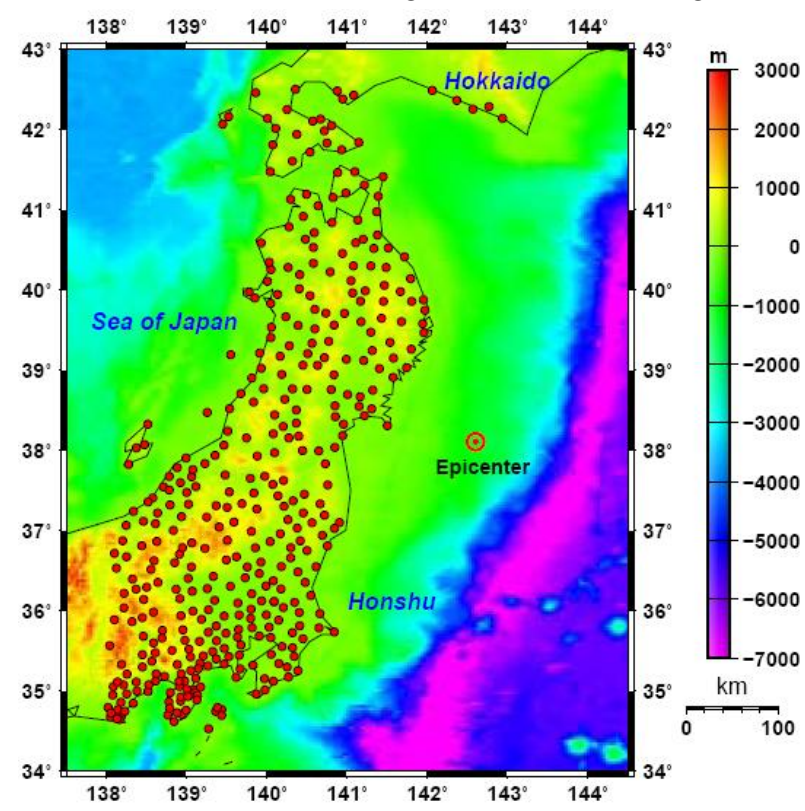

Fig. 1. The spatial distribution of 396 GPS sites

The time series of coseismic displacement can be obtained from high-rate GPS observables. Three-dimensional displacement process at No. 0550 site, nearest to epicenter, time span UTC 05:45:00 05:55:00, is shown in figure 2 . We can see that the site began to move eastward for 18 seconds after the earthquake, then move southward and finally 
downward. The largest displacement was obviously higher than the permanent displacement. It means near-field ground displacement presented elastic motion pattern. The ground movement contains both the static permanent displacement and the dynamic largest displacement. Compared with the permanent displacement, the largest displacement can lead to bigger destruction to inelastic structure and non-fixed objects. Here we put the focus on analyzing the coseismic largest displacement to obtain the motion attenuation pattern.
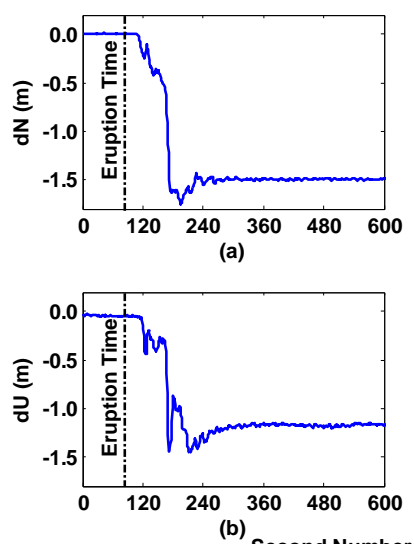

(b)

Fig. 2. Three-dimensional displacement time series at No.0550 site

\section{DiSPlaCEMENT ATTENUATION MODELING}

The earlier displacement attenuation models had to consider the influence of seismic source parameters, propagation media and site environment. Different from these models, this paper proposes a new idea without considering seismic parameters. On the basis of the enough observables from high precision high-rate GPS array, the displacement attenuation pattern can be derived from the data. The quantitative function model between coseismic displacement and epicentral distance and rupture angle can be obtained from the displacement data at 396 observation sites.

The epicentral distance and geodetic azimuth for the connection line from epicenter to GPS site can be calculated using classical geodetic formula. Rupture angle is used to describe seismic wave propagation direction. It is defined as the clockwise angle starting from the fault strike direction, for this case 198 degrees ${ }^{[9]}$.

\section{A. Correlation between Coseismic Displacement and}

\section{Epicentral Distance}

In order to analyze the correlation between coseismic displacement and epicentral distance, 4 groups of data were selected from east component of largest displacement. The rupture angles are $34^{\circ}, 46^{\circ}, 75^{\circ}$ and $114^{\circ}$ respectively.

The correlation coefficient, standard error, corrected Akaike information criterion (AICC) and RMS were jointly used to evaluate the reliability of the model. On the basis of analyzing some optional models ${ }^{[10]}$, the Logistic Power model was selected to describe the relationship between the displacement and epicentral distance, which can be written as follows.

$$
D=\frac{a}{1+(R / b)^{c}}
$$

where $D$ indicates the coseismic displacement, $R$ is epicentral distance from GPS site to epicenter, $a, b$ and $c$ indicate respectively the modeling coefficients.

The calculation results from 4 groups of data are shown in figure 3 . We can see that the correlation coefficients between displacement and epicentral distance are very close to 1.000 , which means strong correlation. The RMS of residual values is between $0.021 \sim 0.064 \mathrm{~m}$, which matched well the coordinate precision.

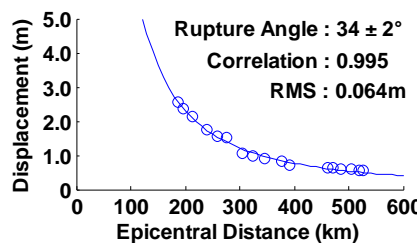

(a)

(c)

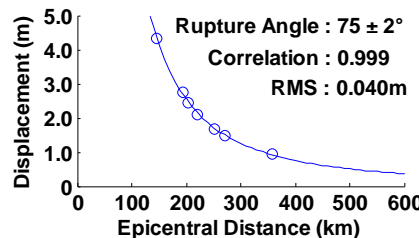

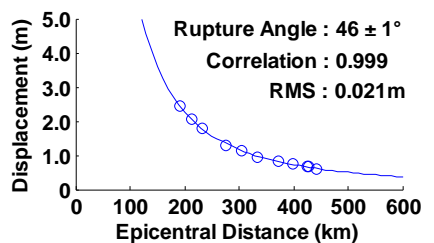

(b)

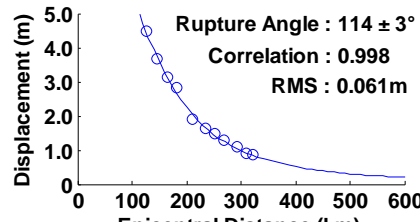

Epicentral Distance (km)

(d)
Fig. 3. The correlation between displacement and epicentral distance

\section{B. Correlation between Cosesimic Displacement and Rupture} Angle

In order to analyze the correlation between coseismic displacement and rupture direction, 4 groups of data are selected from east component of coseismic largest displacement. The epicentral distances are $200 \mathrm{~km}, 250 \mathrm{~km}$, $300 \mathrm{~km}$ and $350 \mathrm{~km}$ respectively. Using the same evaluation method as mentioned above, the selected Cosine model can be written as follows.

$$
D=a+b^{*} \cos \left(c^{*} A+d\right)
$$

where $D$ indicates the coseismic displacement, $A$ is the Rupture Angle, $a, b, c$ and $d$ are respectively the modeling coefficients.

The calculation results from 4 groups of data are shown in figure 4 . The correlation coefficients between coseismic displacement and rupture angle are between 0.749 and 0.937 , which means good correlation. The RMS of residual values is between $0.058 \sim 0.149 \mathrm{~m}$, which is slightly less than the coordinate precision. 

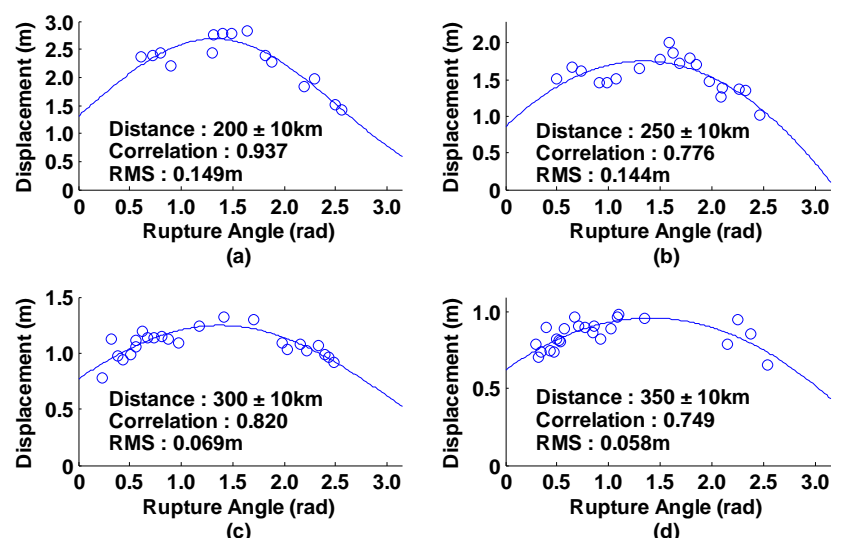

(d)

Fig. 4. The correlation between displacement and rupture angle

\section{Correlation between Displacement and Epicentral}

\section{Distance and Rupture Angle}

Combining the equation (1) and (2), a new displacement attenuation model can be established as the following.

$$
D=a+\frac{b^{*} \cos \left(c^{*} A+d\right)}{1+(R / e)^{f}}
$$

where $D$ indicates displacement, $R$ is epicentral distance, $A$ is rupture angle, $a, b, c, d, e$ and $f$ are respectively the modeling coefficients.

In order to reduce the influence of random error, the displacement data at 386 sites were used to model the pattern. The remaining 10 sites (Nos. 0142, 0893, 0543, 0930, 0198, 0240, 0222, 0216, 0613 and 0227) were used as the checking points. The derived detailed model between coseismic displacement and epicentral distance and rupture angle can be expressed as the following.

$$
D=0.492+\frac{7.178 * \cos (-0.798 * A+1.079)}{\left(1+(R / 15.233)^{3.277}\right.}
$$

The correlation for this model reaches 0.992 with RMS $0.114 \mathrm{~m}$. The statistical residuals at 10 sites are listed in the table 1 . The maximum value is 0.105 , the average $0.061 \mathrm{~m}$ and RMS $0.068 \mathrm{~m}$. The results show that the fitting function was feasible and reliable for modeling the relationship between coseismic displacement and epicentral distance and rupture angle.

Table 1 Residuals at the checking points

\begin{tabular}{cccc}
\hline No. & $\begin{array}{c}\text { Epicentral } \\
\text { Distance } \\
(\mathrm{km})\end{array}$ & $\begin{array}{c}\text { Rupture } \\
\text { Angle } \\
(\mathrm{Rad})\end{array}$ & $\begin{array}{c}\text { Residual } \\
(\mathrm{m})\end{array}$ \\
\hline 0142 & 460.564 & 2.822 & 0.058 \\
0198 & 220.568 & 1.201 & 0.087 \\
0216 & 271.071 & 0.466 & 0.047
\end{tabular}

\begin{tabular}{llll}
0222 & 344.663 & 0.703 & 0.016 \\
0240 & 347.163 & 1.022 & 0.035 \\
0543 & 244.855 & 2.263 & 0.060 \\
0613 & 428.164 & 0.695 & 0.071 \\
0893 & 438.096 & 2.424 & 0.104 \\
0930 & 230.356 & 1.685 & 0.105 \\
3026 & 383.885 & 0.449 & 0.029 \\
\hline
\end{tabular}

\section{CONCLUSION}

On the basis of the displacement observables from high-rate GPS array associated with the Mw9.0 earthquake in Japan, a new attenuation model considering epicentral distance and rupture angle is proposed. The computation results show that the quantitative modeling has good reliability for describing the coseismic displacement attenuation pattern without considering the influence of seismic wave propagation medium and seismic source parameters.

\section{ACKNOWLEDGEMENT}

This work was jointly supported by the Natural Science Foundation of China (Grant Nos. 51178404, 41072220) and the Fundamental Research Funds for the Central Universities (Grant Nos. SWJTU11BR015, SWJTU09CX010, SWJTU12ZT07). The authors are very grateful to the organizations Geospatial Information Authority, Nippon GPS Data Service, Hitachi Zosen Co., GPS Solutions and VERIPOS.

\section{REFERENCES}

[1] Ye Lieping, Ma Qianli, Miu Zhiwei. Study on Earthquake Intensities for Seismic Analysis of Structures [J]. Journal of Earthquake Engineering and Engineering Vibration, 2009, 29(4):9 22.

[2] Liu Huixian, Zhang Qihao. Characteristics of Ground Motion and Earthquake Damages[J]. Earthquake Research In China, 1985, 1(1):35 40.

[3] Medvedev S W, Sponheuer W, Karnik V. Seismic Intensity Scale Version MSK 1964 [C]. The International Association of Seismology and Physics of the Earth's Interior, Paris, 1965.

[4] Zhang Chaojun, LI Weidong, LI Dahui, etc. Discussion on the Seismic Intensity Distribution Calculated by Coseismic Deformation Theory[J]. Earthquake, 2011, 31(1):98 106.

[5] Joyner W, Boore D. Peak Horizontal Acceleration and Velocity From Strong-Motion Records Including Records From the 1979 Imperial Valley, California, earthquake[J]. Bulletin of the Seismological Society of America, 1981 71(6):2011-2038.

[6] Ambraseys N, Srbulov M. Attenuation of Earthquake-Induced Ground Displacements[J]. Earthquake Engineering and Structral Dynamics, 1994, 23:467-487. 
[7] Chen Peishan, Li Baokun, Bai Tongxia. The Attenuation Research of the Strong Ground Displacement in China[J]. Chinese Journal of Geophysics, 1999, 42(4): 495-507.

[8] Imakiire T, Nakahori Y. GPS Earth Observation Network (GEONET) of Japan [C]. New Technology for a New Century, Seoul, 2001.

[9] Shao Zhigang, Wu Yanqiang, Jiang Zaisen, etc. The Analysis of Cosismic Sip and Near-field Deformation about Japanese 9.0 Earthquake Based on the GPS Observation[J]. Chinese Journal of Geophysics, 2011, 54(9):2243-2249.

[10] Huo Junrong, $\mathrm{Hu}$ Yuxian. Study on Attenuation Laws of Ground Motion Parameters[J]. Earthquake Engineering and Engineering Vibration, 1992, 12(2):1-11. 